\title{
ESPAÇOS NÃO FORMAIS: POTENCIALIDADES PARA A INCLUSÃO DE PESSOAS COM NECESSIDADES EDUCACIONAIS ${ }^{*}$
}

\author{
Carla Dornela Tressa ${ }^{1}$ \\ Luciana Lima de Albuquerque da Veiga ${ }^{2}$
}

\section{INTRODUÇÃO}

O processo de educação, como entendido pela maioria das pessoas, considera que a escola é o único ambiente correto e fundamental para a construção do conhecimento, desta forma desconsiderando a exploração de outros espaços, e por sua vez limitando o processo de ensino-aprendizagem.

Conforme descreve Orlandi (2013):

A escola apesar de ser importante, nem sempre cumpre seu objetivo de contribuir de forma significativa, devido às limitações existentes para a abordagem dos vários temas que estão apresentados no currículo escolar, tendo a construção do conhecimento realizada exclusivamente por um professor que se utiliza de um conjunto de disciplinas e atividades preestabelecidas para fornecer o conteúdo considerado fundamental para a formação dos alunos.

Mas é preciso considerar que a educação ou formação pode ser realizada em outros espaços, que são denominados como não for-

\footnotetext{
*DOI - 10.29388/978-65-86678-08-6-0-f.37-46

${ }^{1}$ PPG em Educação em Ciências e Matemática, UFRRJ.

E-mail: carlatressa@yahoo.com.br

${ }^{2}$ PPG em Educação em Ciências e Saúde, NUTES-UFRJ.

E-mail: lucianalimaveiga@gmail.com
} 
mais, que incluem, por exemplo: Centro de Ciências, Museus, Parque Educativo, Parques Naturais, Praças e Praias.

Segundo Vieira et al, (2005); Gohn, (2006):

Esses locais se diferenciam não apenas pelas suas características, mas também pela possibilidade da presença de um instrutor que possua a informação e possa contribuir, sem a formalidade das escolas e universidades, para a obtenção do conhecimento dos envolvidos.

Além disso, o grande potencial dos espaços não formais como amplificador do aprendizado é a sua capacidade de promover uma educação inclusiva, pois nesses espaços há uma diversidade de formas de demonstração/apresentação dos conceitos científicos, possibilitando a assimilação do conhecimento de forma mais lúdica, contextualizada, significativa e realista. Sendo assim, os ENFE apresentam grande importância enquanto espaço pedagógico capaz de contribuir para o processo de ensino-aprendizagem de pessoas com necessidades educacionais. Para discutir este tema foi adotada a pesquisa conceitual qualitativa e tem como objetivo geral discutir as potencialidades dos ENFE como espaço pedagógico e de divulgação científica capazes de promover a inclusão de pessoas com necessidades educacionais.

\section{ESPAÇOS NÃO FORMAIS DE EDUCAÇÃO (ENFE)}

Os ENFE são espaços propícios para auxiliar a escola na complementação do processo educacional de forma a atingir objetivos educacionais diversificados e muitas vezes amplificados.

A emergência da expressão Espaço Não Formal para conceito de pesquisa é recente, e se origina das pesquisas de Educação Não Formal e Divulgação Científica em museus, mas nos últimos anos tem se apropriado para uso pedagógico de ensino for- 
mal em ambiente fora da escola para diversos componentes curriculares e variados níveis de ensino. (SANTOS e TERÁN, 2013, p. 10).

Mas é importante ressaltar que as experiências fora da escola devem ser mediadas de perto pela escola para que os objetivos educacionais estejam devidamente definidos e sejam a todo tempo lembrado pelo educador. Esses cuidados tornam essa experiência mais produtiva e significativa para os estudantes.

De acordo com Lorenzetti e Delizoicov (2008):

[...] a escola na atualidade não é a única responsável pelo processo educacional, ou seja, pela construção do conhecimento, existem outros espaços envolvidos, onde são desenvolvidas atividades didático-pedagógicas como aulas práticas, saídas a campo, feiras de ciências, por exemplo, e que podem propiciar uma aprendizagem significativa contribuindo para um ganho cognitivo.

A utilização dos ENFE para apresentação de conceitos deve ser inserida no processo educacional com o objetivo de diversificar e elevar o ensino a outros patamares, visto sua alta capacidade de fornecer experiências informais e que contribuem para uma contextualização dos conceitos científicos.

Os museus de ciências são espaços dedicados à divulgação e educação científica, e são caracterizados como locais que possuem uma forma própria de desenvolver sua dimensão educativa, buscando diferenciá-los das experiências formais de educação, como aquelas desenvolvidas na escola, e das experiências informais, geralmente associadas ao âmbito da família (MARANDINO, 2008, p. 13).

Conforme Marandino, Selles e Ferreira (2009) apontam, a discussão e a importância dos espaços não formais vêm crescendo parale- 
lamente à tecnologia, o desenvolvimento científico e a necessidade de se alfabetizar cientificamente. Mas chamam atenção para que o campo da educação não formal não aconteça como uma negação do espaço da escola e sim como uma proposta de espaço que a complemente. De acordo com Gadotti (2005):

As escolas precisam conhecer o meio em que vivem seus alunos para construir uma nova cultura escolar que leve em conta a identidade cultural do aluno. A união da educação não formal com a formal poderá contribuir para uma integração mais estreita entre direitos humanos e educação, pois a complementaridade entre o sistema formal e a oferta de educação não formal, reforça os modos alternativos de aprendizagem.

A capacidade dos ENFE atuarem na complementaridade do processo educacional pode ser vista não somente no que tange os aspectos relacionados a apresentação dos conceitos, mas também na capacidade de oferecer acesso a um ambiente diversificado com uma estrutura interativa e tecnológica que algumas escolas não conseguem oferecer visto a deficiência de recursos, infraestruturas e material didático. Sendo assim, os ENFE são capazes de fomentar o processo educativo contribuindo de forma a minimizar essa carência com excelência.

\section{ESPAÇOS NÃO FORMAIS E A EDUCAÇÃO INCLUSIVA}

Diante do contexto atual da educação inclusiva, o professor possui papel fundamental de mediador, entre o conhecimento e o aluno e muitos docentes carregam consigo a dificuldade da prática, quando diante de um sistema educacional engessado, não consegue se adaptar, modificar, inovar para realmente atender os alunos com necessidades educacionais. Sendo assim, a educação não formal, é uma opção que deveria integrar a educação formal em prol do desenvolvimento de uma práxis educativa, que realmente olhe para o contexto 
do aluno, e lhe proporcione a autonomia de se construir diante dos desafios da vida social.

A inclusão social é um tema complexo e que merece ser pensado e discutido com atenção proporcional a sua complexidade para que se desenvolvam medidas educativas consistentes e eficazes capazes de atender a diversidade de cenário que os educadores se deparam na escola e no contexto social.

A inclusão está ligada a todas as pessoas que não têm as mesmas oportunidades dentro da sociedade. Mas os excluídos socialmente são também os que não possuem condições financeiras dentro dos padrões impostos pela sociedade, além dos idosos, os negros, e aqueles com deficiências físicas, como cadeirantes, deficientes auditivos, visuais e mentais. A inclusão social significa tornar essas pessoas participantes da vida social, econômica e política do país (FERREIRA; REAL, 2009).

De acordo com o MEC, o Plano Nacional de Educação (PNE) determina diretrizes, metas e estratégias para a política educacional no período de 2014 a 2024. Neste documento são definidas 20 metas com indicadores específicos para acompanhamento do atendimento dessas metas. A meta 4 é a meta relacionada a inclusão conforme descrito no PNE:

Meta 4: Universalizar, para a população de 4 (quatro) a 17 (dezessete) anos com deficiência, transtornos globais do desenvolvimento e altas habilidades ou superdotação, o acesso à educação básica e ao atendimento educacional especializado, preferencialmente na rede regular de ensino, com a garantia de sistema educacional inclusivo, de salas de recursos multifuncionais, classes, escolas ou serviços especializados, públicos ou conveniados. (Plano Nacional de Educação)

Para acompanhamento dessas metas o PNE tem um projeto de monitoramento chamado "Observatório", no entanto, não há dados 
para o monitoramento da meta 4. As pesquisas e o Censo Demográfico do Instituto Brasileiro de Geografia e Estatística (IBGE) não buscam informações suficientes que permitiriam identificar como está a inclusão nas escolas das pessoas de 4 a 17 anos com deficiência, transtornos globais do desenvolvimento e altas habilidades ou superdotação. Esse é mais um sinal da indiferença histórica e persistente em relação ao tema.

Esta é uma evidência de que é preciso um esforço para pensar e desenvolver de forma ativa um conjunto de meios e ações que contribuam para minimizar constantemente a exclusão e oferecer cada vez mais oportunidades iguais a todos.

Pois pessoas com necessidades educacionais requerem um atendimento educacional especializado, que envolve mudanças estruturais, formação especializada, além de recursos multifuncionais e estes muitas vezes não estão disponíveis no espaço escolar. Os ENFE podem ser uma alternativa para contribuir no atendimento destas necessidades e auxiliar no desenvolvimento de uma educação inclusiva. Os ENFE oferecem conteúdos muito diversificados e as informações contidas nesses espaços têm tratamento específico para torná-las acessíveis e fazerem sentido para os mais variados públicos.

Os ENFE são capazes de atuar em três campos da aprendizagem:

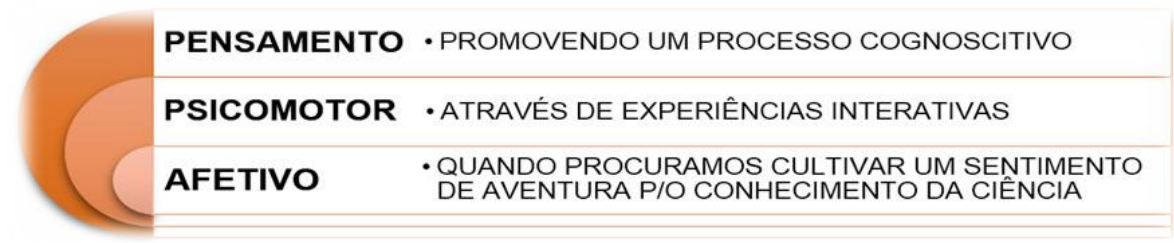

Portanto, considerando esse complexo contexto didático-pedagógico dos ENFE acreditamos no grande potencial deles para ampliar o acesso de pessoas com necessidades educacionais ao conhecimento científico e contribuir para a construção do conhecimento. Pois é por meio do ato de pensar em estratégias e formas de possibilitar o acesso 
ao conhecimento científico, que estaremos desde já promovendo a inclusão social.

Figura 1. Museu do Amanhã (RJ) proporcionando experiências científicas para cadeirantes.

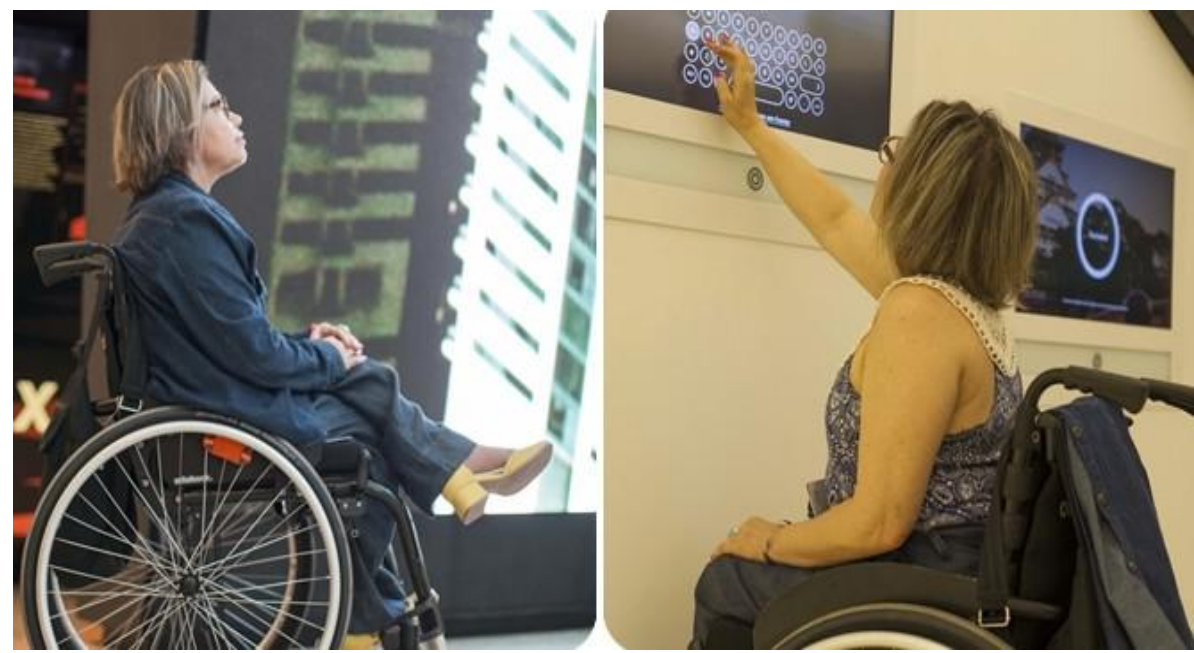

Fonte: http://cadeiravoadora.com.br/museu-do-amanha-por-que-voce-deve-conhe$\underline{\mathrm{cer} / /}$

Figura 2. Museu de Viena (Áustria): Exposição para cegos com impressora 3D.

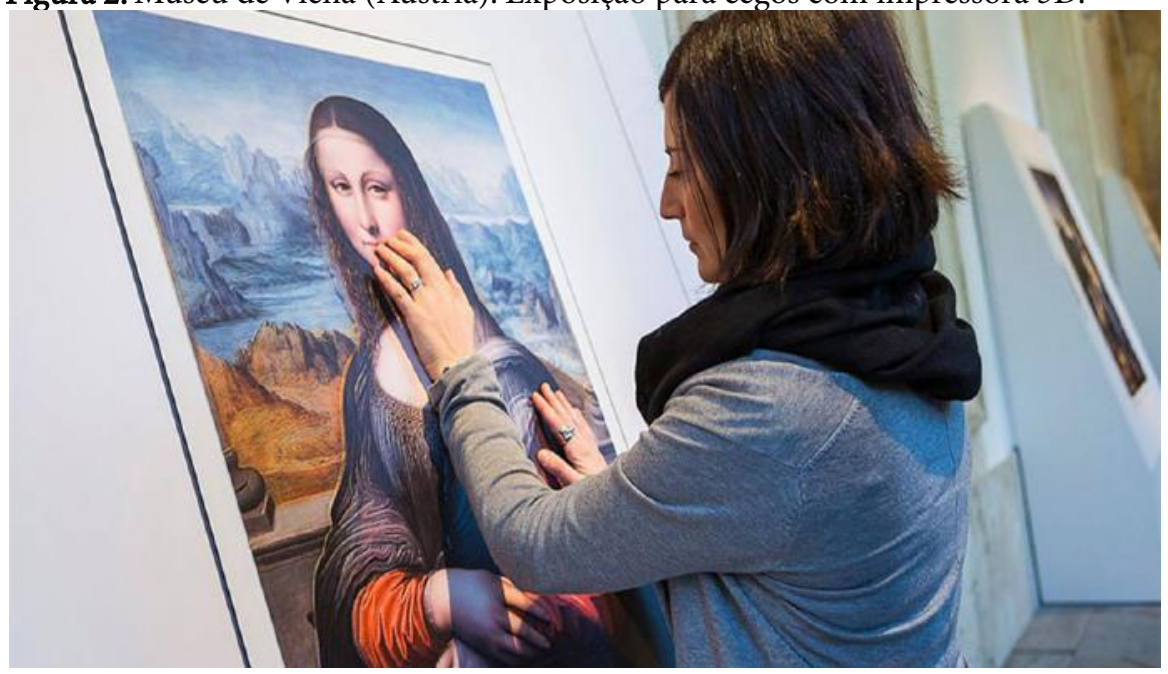

Fonte: https://www.mixfmpoa.com.br/museu-de-viena-inaugura-exposicaopara-cegos-com-impressora-3d 
Figura 3. Museu de Artes e Ofícios (MG): Ferramenta e utensílios podem ser tocados e manipulados pelos cegos.

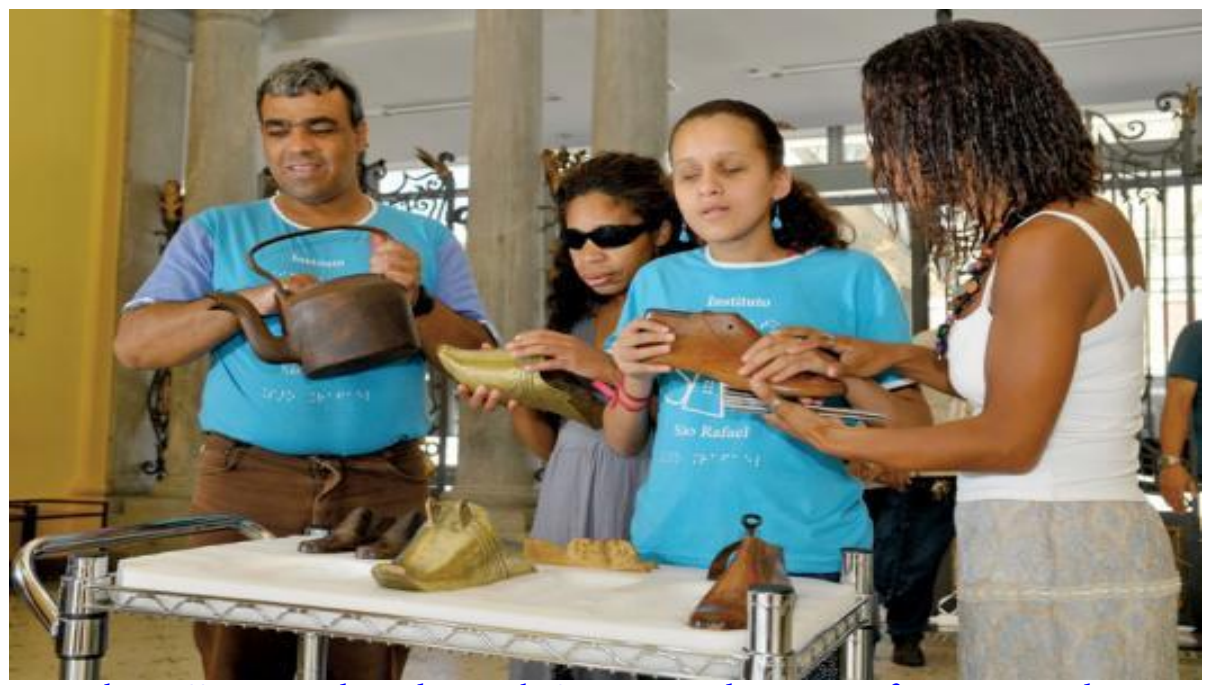

Fonte: https://turismoadaptado.com.br/no-museu-de-artes-e-oficios-o-passado-napalma-da-mao-para-deficientes-visuais/

\section{REFERÊNCIAS}

DELIZOICOV, Demétrio; LORENZETTI, Leonir. Alfabetização científica no contexto das séries iniciais. Ensaio Pesquisa em educação em Ciências, v. 3, n. 1, p. 37-50, 2008.

FERREIRA, Katia Regina; REAL, Caio Lemos. Inclusão social: promovendo a Igualdade. 2009.

GOHN, M. G. Educação não-formal, participação da sociedade civil e estruturas colegiadas nas escolas. Ensaio: avaliação, políticas públicas em Educação, v. 14, n.50, p. 27-38, 2006.

MARANDINO, M. Educação em museus: a mediação em foco. São Paulo, SP: Geenf / FEUSP, 2008.

MARANDINO, M.; SELLES, S. E.; FERREIRA, M. S. Ensino de Biologia: histórias e práticas em diferentes espaços educativos. São Paulo: Cortez, 2009.143-146-147p. 
GADOTTI, Moacir. A questão da educação formal/não-formal. Droit à l'education: solution à tous les problèmes sans solution? Institut International des droits de l'enfant, Sion, 2005.

ORLANDI, L. A. A brincadeira e as atividades formais de ensino no primeiro ano do ensino fundamental: uma análise das manifestações das crianças de seis anos. Dissertação (Mestrado em Educação). Presidente Prudente: UNESP, 2013.

PAASJM - Parque Arqueológico e Ambiental São João Marcos. Disponível em: <http://www.saojoaomarcos.com.br/index.asp > Acesso em 05 mar. 2019.

Projeto observatório do Plano Nacional de Educação (PNE). Disponível em < http://www.observatoriodopne.org.br/home/4/7/\#a-plataforma> Acesso em 04 de mar.de 2019.

SANTOS, S. C.; TERÁN, A. M. O Uso da Expressão Espaços Não Formais no Ensino de Ciências. Rev. ARETÉ. Manaus, v. 6, n. 11, p.01-15, jul-dez 2013.

VIEIRA, V.; BIANCONI, M. L.; DIAS, M. Espaços não-formais de ensino e o currículo de ciências. Ciência e Cultura, v.57, n 4, p. 21-23, 2005. 
